\title{
OS 100 ANOS DA DOENÇA DE CHAGAS NO BRASIL
}

\author{
A hundred years of Chagas disease in Brazil
}

\author{
Nelson Adami ANDREOLLO' ${ }^{1}$, Osvaldo MALAFAIA ${ }^{2}$
}

ABCDDV/670

Andreollo NA, Malafaia O. Os 100 anos da doença de Chagas no Brasil. ABCD Arq Bras Cir Dig 2009;22(4):189-91

A história da doença de Chagas se inicia no interior de Minas Gerais, com as pesquisas de um jovem médico sanitarista e pesquisador do Instituto Osvaldo Cruz: Carlos Justiniano Ribeiro Chagas (1879-1934, natural de Oliveira - MG), que em abril de 1909, comunicou ao mundo científico a descoberta de uma nova doença humana. Seu agente etiológico um protozoário que denominou de Trypanosoma cruzi, em homenagem ao seu mestre Oswaldo Cruz e o inseto transmissor, o triatomídeo conhecido como "barbeiro". Por esta descoberta, Carlos Chagas recebeu indicação para Prêmio Nobel da Medicina.

Os dados epidemiológicos mais recentes demonstram que a doença de Chagas continua sendo considerada como problema de saúde pública em 19 países americanos de colonização ibérica, nas regiões rurais e nas grandes cidades para onde convergiram pessoas infectadas pelo parasito. Atualmente é a quarta causa de morte no Brasil entre as doenças infecto-parasitárias nas faixas etárias acima de 45 anos. É também calculada uma proporção de entre 10 e $40 \%$, entre os infectados, aqueles que já têm ou que terão cardiopatia crônica, sendo que deste total pelo menos 10 \% apresentarão forma grave que será provavelmente a causa principal de óbito. Nos dias de hoje é prevalente em populações rurais, onde encontram-se milhares de insetos vetores nas moradias de madeira e barro e estima-se que haja cerca de 12 a 14 milhões de pessoas infectadas na América Latina, 300.000 casos novos por ano, com dois a três milhões de pacientes com complicações crônicas da moléstia atingindo 21.000 óbitos / ano.

A transmissão do parasito faz-se principalmente por intermédio do vetor, o "barbeiro" e segue-se em importância a transmissão transfusional e a congênita, que vem sendo cada vez mais estudada. Ocorrem ainda a transmissão por acidente de laboratório, por leite materno, por ingestão de formas tripomastigotas dissolvidas em bebidas, como suco de cana e açaí, em que os insetos vetores foram triturados

${ }^{1}$ Presidente do Colégio Brasileiro de Cirurgia Digestiva;

${ }^{2}$ Editor Científico do ABCD - Arquivos Brasileiros de Cirurgia Digestiva

Correspondência: Osvaldo Malafaia, e-mail: malafaia@ evangelico.org.br durante o preparo ou suas fezes contaminaram o alimento, mas com pouco significado epidemiológico.

A principal forma de controle da doença para a transmissão por vetores é feita com produtos químicos aplicados diretamente nas moradias, para combater os insetos. Entretanto a melhor e mais eficaz forma são os programas de melhoria de moradias rurais construindo casas de alvenaria para a população de risco, em que insetos vetores não consigam colonizar.

No Brasil, com a progressiva melhora do Sistema Único de Saúde, houve avanços consistentes em relação à atenção aos pacientes chagásicos. Tanto no que se refere ao tratamento dos cardiopatas e a colocação de marca-passos, quanto às intervenções cirúrgicas no aparelho digestivo, resultando em melhor e maior conforto e qualidade de vida às pessoas portadoras das formas clínicas da doença.

Desde a descoberta da doença de Chagas em 1909 que a mesma passou a ser considerada uma das possíveis causas do mal de engasgo, afecção endêmica existente no Brasil, cuja sintomatologia é a mesma da acalásia do esôfago, de ocorrência universal. Caracteriza-se pela perda do peristaltismo esofagiano e falta de relaxamento do esfíncter inferior às deglutições, o que acarreta dificuldade de ingestão dos alimentos, que ficam em grande parte retidos no esôfago, causando a progressiva dilatação deste órgão. A semelhança das duas afecções levou muitos autores a acreditar que se tratasse de uma mesma e única entidade mórbida. $\mathrm{O}$ que as distinguia era a inusitada frequência do mal de engasgo em certas regiões do Brasil, em contraste com a raridade da acalásia em qualquer país do mundo.

A primeira referência quanto à possibilidade da etiologia chagásica do "mal de engasgo" é do próprio Carlos Chagas em seu trabalho publicado em 1916. Referindo-se à associação estreita das duas doenças, assim se expressou: “...será o mal de engasgo um elemento a mais da Trypanosomíase brasileira e essa disfagia das formas agudas traduzirá a fase inicial da syndrome?’. E a seguir menciona que. “...tornam-se precisas novas pesquizas que autorizem, de modo irrecusável, incluir o mal de engasgo na sintomatologia multiforme da infecção pelo Trypanosoma cruzi.."(texto na grafia original). Nos anos seguintes, também o megacólon foi incluído como consequência do 
mesmo agente etiológico e da doença.

A comprovação histológica veio nas décadas de 50 e 60 com as pesquisas de um estudioso austríaco em Ribeirão Preto, SP, Brasil Fritz Koeberle, que constatou haver na fase aguda da infecção e parasitismo da parede muscular do trato digestivo e processo inflamatório envolvendo o plexo mioentérico e na fase crônica a desnervação tanto do esôfago como do cólon. Na contagem dos neurônios, que era feita no terço inferior do esôfago, a redução do número deles era uma constante nos chagásicos, porém menos intensa naqueles casos de esôfago aparentemente normal. E estudos quantitativos foram igualmente feitos em relação ao cólon, demonstrando que a desnervação não se restringia ao segmento dilatado, comumente reto e sigmóide, mas a todo o cólon.

A partir destes estudos, outros pesquisadores constataram que a desnervação também ocorre em outros segmentos do trato digestivo: estômago, duodeno, intestino delgado, apêndice cecal e cólon, demonstrando, em todos eles, significativa redução do número de neurônios. E é claro, quanto à cardiopatia chagásica, Koeberle constatou do mesmo modo redução do número de células nervosas em todo o coração.

Joffre Marcondes de Rezende em 1956 em Goiânia, GO, Brasil, propôs a denominação de forma digestiva para caracterizar as manifestações decorrentes das “...lesões do tubo digestivo com as consequentes alterações da motilidade"..., denominação esta amplamente aceita. Em 1959, o mesmo autor estudioso até hoje da doença de Chagas, ampliou o conceito de forma digestiva para abranger, além das desordens motoras, as alterações secretoras e absortivas do aparelho digestivo, já conhecidas ou que viessem a ser descritas no futuro, independentemente da presença ou não de dilatação esofágica ou colônica.

O duodeno, depois do esôfago e do cólon, é o segmento que mais vezes se apresenta dilatado, sendo denominado de megaduodeno e quase sempre está associado a outras visceromegalias. A dilatação pode localizar-se no bulbo (megabulbo), na segunda e terceira porções e comprometer todo o arco duodenal. Mesmo não ocorrendo dilatação é frequente a discinesia e já foi documentado a hiper-reatividade ao estímulo colinérgico decorrente da desnervação.

No intestino delgado os estudos histopatológicos evidenciaram desnervação do sistema nervoso entérico, porém bem menos acentuada do que a do esôfago e do cólon. Ocorrendo dilatação, pode-se caracterizar como megajejuno ou megaíleo, entidades raras da doença, havendo poucos relatos na literatura.

As repercussões clínicas da denominada enteropatia chagásica são pouco evidentes, porém podem ser investigadas em estudos direcionados para esse fim, tendo sido comprovadas alterações motoras, tanto em estudos radiológicos como manométricos. O complexo motor migratório interdigestivo apresenta anormalidades em pacientes com outras manifestações da forma digestiva. Além disso, estudos sobre a absorção intestinal em portadores da forma digestiva mostraram absorção acelerada de glicose e outros açúcares. Em consequência deste fato, a prova de tolerância oral à glicose pode apresentar curvas glicêmicas anormais, com hiperglicemia transitória na primeira hora. E justamente com a hiperabsorção glicídica foi constatado hipo-absorção lipídica de grau leve, não alterando significativamente o teor da gordura fecal.

A vesícula biliar sofre também desnervação, passando a apresentar alterações motoras de enchimento e esvaziamento, e estudos manométricos no esfíncter de Oddi revelaram alterações em doentes chagásicos. Pode-se dizer que a colecistomegalia bem como a dilatação do colédoco nos chagásicos. Por outro lado, há publicações que mostram maior incidência de colelitíase em pacientes chagásicos portadores de megaesôfago e/ou megacólon.

Quanto ao pâncreas, a porção exócrina tem a sua capacidade funcional preservada, tendo sido documentado deficiência secretora por estímulo indireto, decorrente de alterações na liberação de hormônios duodenojejunais.

As glândulas salivares, principalmente as parótidas, apresentam-se hipertrofiadas nos pacientes com megaesôfago, e estes doentes têm hiper-salivação em consequência ao reflexo esofagossalivar exacerbado. Estudos demonstraram que esta hiper-salivação e a hipertrofia das parótidas persistem em pacientes esofagectomizados, o que demonstra não se tratar apenas do complexo esofagossalivar e sim do comprometimento da inervação dessas glândulas na doença de Chagas.

Os ilustres gastroenterologistas Romeu Cançado, Pedreira de Freitas, A Brasil, Calil Porto, Uysses Meneghelli, Renato Godoy, Agostinho Bettarello, Heitor Rosa, Luiz de Paula Castro e muitos outros deram suas contribuições.

Avanços formidáveis no tratamento cirúrgico do megaesôfago e megacólon ocorreram contribuindo para a melhoria da qualidade de vida dos doentes e da sua sobrevida, tanto nas formas avançadas como não avançadas. Destaques devem ser feitos à fundoplicatura em três camadas associada à cardiomiotomia a Heller, e a esofagectomia transmediastinal descritas e padronizadas por Henrique Walter Pinotti, Eugenio Bueno Ferreira e outros colaboradores da Universidade de São Paulo. E no tratamento cirúrgico do megacólon, igualmente contribuíram Alípio Correa Neto, Arrigo Raia, Jorge Haddad, O. Simonsen, Daher Cutait e Angelita Habr-Gama, da mesma Universidade. São citados na literatura José Alfredo dos Reis Neto e Peretz Capelhuhnick pelas contribuições. Além destes, Edmundo Vasconcelos, Câmara-Lopes, Luiz Rassi, Serra-Doria, Rui Ferreira Santos, Ivan Cecconello e Osvaldo Malafaia também não pouparam esforços para melhor tratar os chagásicos. E tantos outros médicos e cirurgiões em todo o País que com suas extensas e minuciosas pesquisas e publicações contribuíram para o diagnóstico, tratamento das formas clínicas e tratamento cirúrgico, que não haveria espaço neste Editorial para citar a todos, mas que certamente são igualmente considerados, valorizados e não esquecidos.

Os avanços foram enormes, tanto que atualmente as operações para megaesôfago e megacólon são já realizadas com auxilio da videolaparoscopia e até mesmo com recursos da cirurgia robótica, para melhor atender e bem tratar ao doente chagásico. 
Por tudo o que foi acima exposto, a cirurgia digestiva e a gastroenterologia tem muito a agradecer e comemorar nestes 100 anos após a magnífica descoberta de Carlos Chagas, que possibilitou em um século milhares de estudos, pesquisas, monografias, teses e publicações sobre a doença. Certamente continua sendo a doença infecto-contagiosa mais estudada nos dias de hoje nas instituições de pesquisa brasileiras, e também muito estudada exterior.

Mesmo assim, aqueles que se interessam pela doença

\section{REFERÊNCIAS}

1. Chagas C. Nova tripanossomíase humana: Estudos sobre a morfologia e o ciclo evolutivo do Schizotrypanum cruzi n. gen., n. sp., agente etiológico de nova entidade mórbida do homem. Memórias do Instituto Oswaldo Cruz. 1909; 1:159-218.

2. Chagas C. Processos patogênicos da tripanossomíase americana. Memórias do Instituto Oswaldo Cruz. 1916; 8:5-35.

3. Rezende JM. Forma digestiva da moléstia de Chagas. Revista Goiana de Medicina. 1959; 5(3): 193-227.

4. Köberle F. Pathologic anatomy of enteromegaly in Chagas disease. Bockus Alimni Internat. Soc.Gastroenterology (Procedings). 1962; 2:92-110. sabem que ainda há muito o que pesquisar. Há vários aspectos não totalmente esclarecidos da sua fisiopatologia, no seu tratamento clínico e avanços no tratamento cirúrgico, incluindo também outros estudos epidemiológicos, genéticos, moleculares e imunológicos. Estas pesquisas devem continuar de maneira incessante, pois no futuro um outro brasileiro, por esse tema, ainda poderá ser indicado e merecedor de um Prêmio Nobel da Medicina!

5. Dias JCP. Carlos Chagas: Prêmio Nobel perdido. In Araújo F et al. (orgs.) Carlos Chagas: coletânea de textos publicados sobre sua vida e sua obra. Belo Horizonte, Academia Mineira de Medicina. 2000, p. 212-214.

6. Brasil 2002. Inquérito Sorológico Nacional de Prevalência da Infecção Chagásica. Brasília, Ministério da Saúde, Fundação Nacional de Saúde, 14 pp.

7. Cecconello I, Rocha JRM, Gama-Rodrigues JJ, Pinotti HW. Megaesôfago Chagásico. In: Aparelho Digestivo, Clinica e Cirurgia. Ed. Coelho JCU. $3^{\mathrm{a}}$ Ed. Atheneu, São Paulo, 2005. PP 346-359. 